\title{
Review of Dairy Consumption and Cognitive Performance in Adults: Findings and Methodological Issues
}

\author{
Georgina E. Crichton ${ }^{a}$ Janet Bryann ${ }^{a} b \quad$ Karen J. Murphy ${ }^{a}$ Jonathan Buckley ${ }^{a}$ \\ a Nutritional Physiology Research Centre, Sansom Institute for Health Research, and bSchool of Psychology, \\ University of South Australia, Adelaide, S.A., Australia
}

\section{Key Words}

Dairy food intake $\cdot$ Cognitive functioning $\cdot$ Methodological review

\begin{abstract}
Background: Diet is a modifiable factor that could be targeted as an appropriate intervention to optimise cognitive health and well-being in ageing. Aim: The aim of this systematic review was to consider current evidence for an association between dairy intake and cognitive functioning. Methods: Searches of the electronic databases Medline, Embase, Web of Science, CINAHL, and PsychInfo were undertaken to identify peer-reviewed journal articles that reported on associations between dairy consumption and cognitive outcomes. Results: Three cross-sectional and 5 prospective studies were identified. Poorer cognitive function and an increased risk for vascular dementia were found to be associated with a lower consumption of milk or dairy products. However, the consumption of whole-fat dairy products may be associated with cognitive decline in the elderly. Conclusion: Methodological variability and study limitations do not enable conclusions regarding optimal dairy intake and cognitive performance to be drawn. Randomised controlled trials are needed to confirm the relationship between dairy intake and cognition.
\end{abstract}

Copyright ๑ 2010 S. Karger AG, Basel

\section{Introduction}

As the populations of developed nations around the world age [1], cognitive decline and dementia are emerging as major health problems. Cognitive decline may range from the very minimal decline that is associated with normal ageing, to mild cognitive impairment (MCI), or very severe dementia, with the latter regarded as the clinical end-point of cognitive impairment [2]. The worldwide prevalence of dementia is increasing and is predicted to affect 81.1 million people by 2040 [3], placing a considerable burden on health care resources, and impacting substantially on the quality of life of the individuals afflicted and their families. As the precise aetiology of cognitive decline is not known, and there is no cure, interventions that may slow or prevent this condition have become a health priority.

There is a substantial body of evidence indicating that nutrition may play an important role in the causation and prevention of age-related cognitive decline and dementia $[4,5]$. While positive associations have been shown between a number of nutrients and cognitive performance, including antioxidants, folate, omega- 3 and omega- 6 fatty acids, little attention has been paid to the potential role of dairy foods in modulating psychological parameters. This is despite recent epidemiological, observational and intervention studies providing evidence for the role of dairy in

\section{KARGER}

Fax +4161306 1234 E-Mail karger@karger.ch www.karger.com
Georgina Crichton

Nutritional Physiology Research Centre, University of South Australia

GPO Box 2471, Adelaide, SA 5001 (Australia)

Tel. +61 88302 1452, Fax +61 883022178

E-Mail Georgina.Crichton@ postgrads.unisa.edu.au 
improving cardiovascular risk factors and lowering the prevalence of metabolic syndrome. Dairy consumption may reduce the likelihood of cognitive decline either directly, or via mediating effects on cardiometabolic health.

The primary objective of this review was to identify published literature which has reported associations between dairy consumption and cognitive performance in order to identify whether there is any evidence for a beneficial effect of dairy consumption on cognition.

\section{Methods}

\section{Search Strategy}

A search was undertaken on Medline (1950 to July 2009), Web of Science (1968 to July 2009), Embase (1980 to July 2009), CINAHL (1981 to July 2009), and PsychInfo (1800s to July 2009) for studies that reported an association between dairy intake (or intake of individual dairy products) and cognitive function or psychological health. The search terms used were dairy, milk, cheese, yogurt as isolated words and in combination with food, intake, consumption, and cognition, cognitive decline, cognitive performance, cognitive impairment, cognitive function/dysfunction, cognitive state, dementia, Alzheimer's disease, mild cognitive impairment, depression, mental illness, psychological/mental health. In addition to electronic database searches, additional papers were retrieved by reviewing reference lists of all studies identified in the initial electronic search. Letters, conference proceedings, abstracts of dissertations and reviews were not included but were screened for additional references that met the inclusion criteria.

\section{Inclusion and Exclusion Criteria}

Included papers were limited to studies involving adults only, and written in English language, unless a translation of a non-English paper was readily available. Only studies with a quantitative assessment of dairy food intake were included, i.e. studies which reported a total measure of dairy intake from a number of different dairy products, or studies which measured individual consumption of specific dairy products, such as milk and cheese. Papers deemed eligible for inclusion also had to report at least 1 measure of cognitive function or cognitive status, including the presence or absence of dementia, Alzheimer's disease (AD) or MCI.

\section{Data Extraction and Methodological Appraisal}

Pre-determined information provided in each paper was extracted in order to be summarised for comparison. This included details about the study design (cross-sectional or prospective), the location of the study, and participant characteristics (number, gender and age at baseline and/or follow-up of subjects). Any exclusion criteria were summarised. Detailed information about the measure of cognitive function used was extracted from each paper, including what was assessed (e.g. dementia), how the outcome measure was assessed (e.g. specific questionnaire or clinical criteria), and the definition used to define impairment (e.g. cut-off score or clinical diagnosis). Details provided regarding dairy intake were also extracted. This information included the measure used to quantify dairy intake (e.g. diet recall, food questionnaire), the specific dairy foods measured (e.g. milk, cheese), the serving size of dairy used in analyses, and the fat content of the dairy measured. Details about the study findings included the type of statistical analyses performed, such as adjustments made, the proportion of subjects defined as having cognitive or psychological impairment, and the main findings in regard to a quantity of dairy intake associated with cognitive or psychological function.

The included studies were scored on their methodological quality on the basis of a modified checklist (table 1) developed for observational longitudinal studies [6], and entailed the 6 areas of potential study bias recommended to be included in any quality appraisal component of systematic reviews [7]. Criteria were adapted to allow appraisal of both cross-sectional and longitudinal studies and assessed methodological quality in 6 areas: (1) study participation, (2) study attrition, (3) measurement of predictor variable, (4) measurement of outcome variable, (5) confounding measurement, and (6) analysis. Each criterion was scored as yes (1), no (0), or partly (1/2) based on information provided in the paper, and a total score out of 20 was calculated (see Appendix).

The primary author (G.E.C.) was responsible for all literature searches, assessed the eligibility of each paper, performed all data extraction and conducted the methodological appraisal and scoring. A formal meta-analysis was not performed because of the limited number of studies, the heterogeneity of study design and assessment of both dairy and cognitive (or psychological) functioning, differences in adjustment for confounding, and statistical analyses used to present results.

\section{Results}

\section{Results of the Search}

The literature search yielded a total of 216 citations. After removing duplicates, 132 papers remained. The titles and abstracts of these papers were screened to identify potentially relevant papers for full review. The full text was obtained for 30 papers deemed to be potentially relevant. Eight papers were excluded because they did not include specific measures of cognition, 5 papers examined soy, a milk probiotic or vitamin D and not dairy, 3 papers reported on the influence of food diversity (rather than dairy) on cognition, 3 papers examined dietary intake in schizophrenic populations, 2 papers only reported on associations between dairy intake and survival risk or mortality, and 1 paper was a review.

Based on the selection criteria, 8 papers from 7 different studies were included in this review. Two of the included papers both reported on the Cardiovascular Risk Factors, Aging and Incidence of Dementia (CAIDE) study $[8,9]$ but have been treated as separate studies for the purpose of this review. The papers examined different outcome measures, namely, different aspects of cognition. Eskelinen et al. [8] examined actual cognitive performance as measured by neuropsychological tests, in addition to MCI. An important differentiation is that this paper excluded participants 
Table 1. Checklist for methodological assessment of cross-sectional and longitudinal studies included in the review

Study participation

(1) The population of interest adequately described in terms of key characteristics, and represented by sample

(2) Sampling, recruitment methods, time and place of recruitment adequately described

(3) Inclusion and exclusion criteria adequately described

(4) Baseline characteristics of study sample adequately described (number of participants, age, gender, health status)

Study attrition

Cross-sectional design

(5) Justification or explanation for the number of participants

(6) Explanation of how missing data was dealt with
Longitudinal design

(5) Specification of numbers at each follow-up period and duration of follow-up

(6) Analyses conducted to determine whether participants lost to follow-up do not significantly differ in key characteristics/outcomes from those who completed the study

Measurement of predictor variable

(7) Method used to assess dietary intake adequately described and reference provided

(8) Reliability and validity of measurement tool(s) mentioned

(9) Mean dairy intake adequately described in sample (including type, quantity)

(10) Type of dairy associated with outcome measure of interest clearly described (product and fat content)

(11) Quantity of dairy associated with outcome measure of interest clearly described (number of servings and specified serving size, or amount in $\mathrm{g} / \mathrm{ml}$ per day)

Measurement of outcome variable

(12) Method used to assess cognition adequately described

(13) Cognition measure included that is not a screening tool

(14) Criteria used to diagnose impairment provided (or definition of cognitive impairment provided if not from diagnosis)

(15) Number of participants with cognitive impairment provided (at baseline and/or follow-up)

Confounding measurement

(16) Potential confounders mentioned and accounted for in analyses

Analysis

(17) Specific type of analyses adequately described

(18) Measure of association provided with confidence intervals

(19) Effect sizes reported

(20) The impact of biases/limitations to study assessed qualitatively

Criteria: rated as 1 (yes), 0 (no), 1/2 (partly).

with dementia at the follow-up examination. Laitinen et al. [9] included those with dementia, as dementia and AD were the primary outcome measures. For these reasons, the 2 papers have been added as 2 studies.

\section{Summary of Included Studies}

The included studies consisted of 3 cross-sectional [10$12]$ and 5 prospective studies $[8,9,13-15]$. The follow-up duration of the prospective studies ranged from 3.3 [13] to 30 years [15]. There were no randomised controlled trials identified in the literature that manipulated dairy intake and assessed any changes in cognitive function. Table 2 describes the study design, cohort, location, number and ages of participants, and the exclusion criteria for the studies included in this review, grouped by study design and listed by quality appraisal score in descending order. The predictor and outcome measures used are detailed in table 3 , and the main findings of each study are presented in table 4. All 8 papers were published after the year 2000. Studies were conducted in America ( 1 in the United States, 1 in Mexico), Europe (1 in France, 2 in Finland), Australia (1), and Asia (1 in Korea, 1 in Japan).

\section{Participants}

One study included only males [13], 1 study included only females [14] and the remaining 6 included both genders $[8-12,15]$. Sample sizes ranged from 449 [11] to 4,809 [14]. The majority of studies included middle-aged to elderly populations. In the 3 cross-sectional studies, there were no participants under the age of 40 years. Follow-up 
Table 2. Characteristics of studies reporting associations between dairy consumption and cognition

\begin{tabular}{|c|c|c|c|c|c|c|c|c|}
\hline \multirow[t]{2}{*}{ Study } & \multirow{2}{*}{$\begin{array}{l}\text { Cohort, FUD } \\
\text { (prospective studies) }\end{array}$} & \multirow[t]{2}{*}{ Country } & \multirow{2}{*}{$\begin{array}{l}\text { Age, mean or } \\
\text { range, years }\end{array}$} & \multicolumn{2}{|c|}{ Number } & \multirow{2}{*}{$\begin{array}{l}\text { Exclusion } \\
\text { criteria }\end{array}$} & \multirow[t]{2}{*}{ Adjustments } & \multirow{2}{*}{$\begin{array}{l}\text { Quality } \\
\text { score, } \\
120\end{array}$} \\
\hline & & & & M & $\mathrm{F}$ & & & \\
\hline \multicolumn{9}{|c|}{ Cross-sectional } \\
\hline $\begin{array}{l}\text { Lee } \\
\text { et al. [11] }\end{array}$ & Korean elderly & Korea & $60-83$ & 210 & 239 & $\begin{array}{l}\text { Major cognitive } \\
\text { impairment }\end{array}$ & Age & 8.0 \\
\hline $\begin{array}{l}\text { Avila-Funes } \\
\text { et al. [10] }\end{array}$ & $\begin{array}{l}\text { Study on Health, } \\
\text { Welfare and Aging }\end{array}$ & Mexico & 64.4 & 465 & 1,283 & Nil specified & Nil & 9.5 \\
\hline $\begin{array}{l}\text { Rahman } \\
\text { et al. [12] }\end{array}$ & $\begin{array}{l}\text { Survey of } \\
\text { Alabama's Elderly }\end{array}$ & USA & $55-94$ & 345 & 711 & Nil specified & Age, race, gender, education, dietary factors & 11.5 \\
\hline $\begin{array}{l}\text { Prospective } \\
\text { Almeida } \\
\text { et al. [13] }\end{array}$ & $\begin{array}{l}\text { Australian elderly } \\
\text { men } \\
\text { FUD: } 3.3-6.8 \text { years }\end{array}$ & Australia & $\begin{array}{l}\text { Baseline: } \geq 75 \\
\text { Follow-up: } \geq 80\end{array}$ & 601 & & Nil specified & $\begin{array}{l}\text { Analyses repeated excluding subjects with } \\
\mathrm{AD} \text {, dementia/memory problems, } \\
\text { depression }\end{array}$ & 10.5 \\
\hline $\begin{array}{l}\text { Laitinen } \\
\text { et al. [9] }\end{array}$ & $\begin{array}{l}\text { CAIDE study } \\
\text { FUD: } 21 \text { years }\end{array}$ & Finland & $\begin{array}{l}\text { Baseline: } 50.4 \\
\text { Follow-up: } 71.3\end{array}$ & 549 & 900 & Nil specified & $\begin{array}{l}\text { Age, gender, education, FUD, other fat } \\
\text { subtypes from milk products, ApoE4 status, } \\
\text { vascular risk factors, history of vascular } \\
\text { disorders }\end{array}$ & 11.5 \\
\hline $\begin{array}{l}\text { Yamada } \\
\text { et al. [15] }\end{array}$ & $\begin{array}{l}\text { Adult Health Study, } \\
\text { atomic bomb } \\
\text { survivors } \\
\text { FUD: } 25-30 \text { years }\end{array}$ & Japan & $\begin{array}{l}\text { Baseline: } 35-60 \\
\text { Follow-up: } 60-90\end{array}$ & 475 & 1,299 & Nil specified & Age, sex, education & 11.5 \\
\hline $\begin{array}{l}\text { Eskelinen } \\
\text { et al. [8] }\end{array}$ & $\begin{array}{l}\text { CAIDE Study } \\
\text { FUD: } 21 \text { years }\end{array}$ & Finland & $\begin{array}{l}\text { Baseline: } 50.2 \\
\text { Follow-up: } 71.1\end{array}$ & 506 & 835 & $\begin{array}{l}\text { Dementia at } \\
\text { follow-up }\end{array}$ & $\begin{array}{l}\text { Age, gender, education, FUD, other fat } \\
\text { subtypes from milk products, ApoE4 status, } \\
\text { midlife vascular risk factors }\end{array}$ & 12.5 \\
\hline $\begin{array}{l}\text { Vercambre } \\
\text { et al. [14] }\end{array}$ & $\begin{array}{l}\text { Cohort from the } \\
\text { Epidemiological } \\
\text { Study of Women of } \\
\text { MGEN Study } \\
\text { FUD: } 13 \text { years }\end{array}$ & France & $\begin{array}{l}\text { Baseline: } 62-68 \\
\text { Follow-up: 76-82 }\end{array}$ & & 4,809 & $\begin{array}{l}\text { Energy intake } \\
\text { deemed non- } \\
\text { plausible }\end{array}$ & $\begin{array}{l}\text { Age, education, physical activity, energy } \\
\text { intake, smoking, supplement consumption, } \\
\text { use of postmenopausal hormones, diabetes, } \\
\text { hypertension, hypercholesterolaemia, CHD, } \\
\text { stroke, cancer, depression }\end{array}$ & 16.0 \\
\hline
\end{tabular}

FUD = Follow-up duration; MGEN = Mutuelle Generale de l'Education Nationale. Quality score was calculated on 20 criteria based on the reporting of the study design and method, study attrition, measurement of dairy intake, assessment of cognition, and statistical analysis.

assessments in all prospective studies were conducted in individuals over the age of 60 . Studies recruited elderly people possibly representative of the population in that region $[10,12,13]$, used subsamples of subjects from larger health studies $[8,9,14]$, recruited atomic bomb survivors [15], and elderly people from a welfare centre [11]. Two of the 9 studies excluded those with major cognitive impairment [11] or dementia at follow-up [8].

\section{Assessment of Cognitive Functioning}

A variety of assessment procedures were used to measure cognitive status. Six out of the 8 studies used a dementia screening tool, either the Mini-Mental State Examination or the Mental Status Questionnaire as a measure of cognitive function. For 4 studies, this was the sole measure to determine cognitive function [10-13]. The 2 CAIDE studies $[8,9]$ used the Mini-Mental State Examination in addition to standardised dementia, $\mathrm{AD}$ or $\mathrm{MCI}$ diagnostic criteria. One study applied a number of dementia screen- ing instruments in conjunction with diagnostic criteria [15]. An indirect measure of cognitive function was utilized by Vercambre et al. [14], who sent a cognitive deterioration scale to a close relative or friend of each participant. The informant was required to complete the scale by evaluating any observed cognitive deterioration over the past year. Two studies assessed depression using the Geriatric Depression Scale in addition to cognitive state $[10,13]$.

\section{Assessment of Dairy Intake}

One cross-sectional and 5 prospective studies applied a food frequency questionnaire or self-reported questionnaire including dietary measures to assess dairy intake [8-10, 13-15]. The remaining cross-sectional studies used a 24-hour diet recall [11] and a home interview [12].

\section{Main Findings}

Two cross-sectional studies $[11,12]$ and 1 out of the 5 prospective studies [15] reported a beneficial effect from 


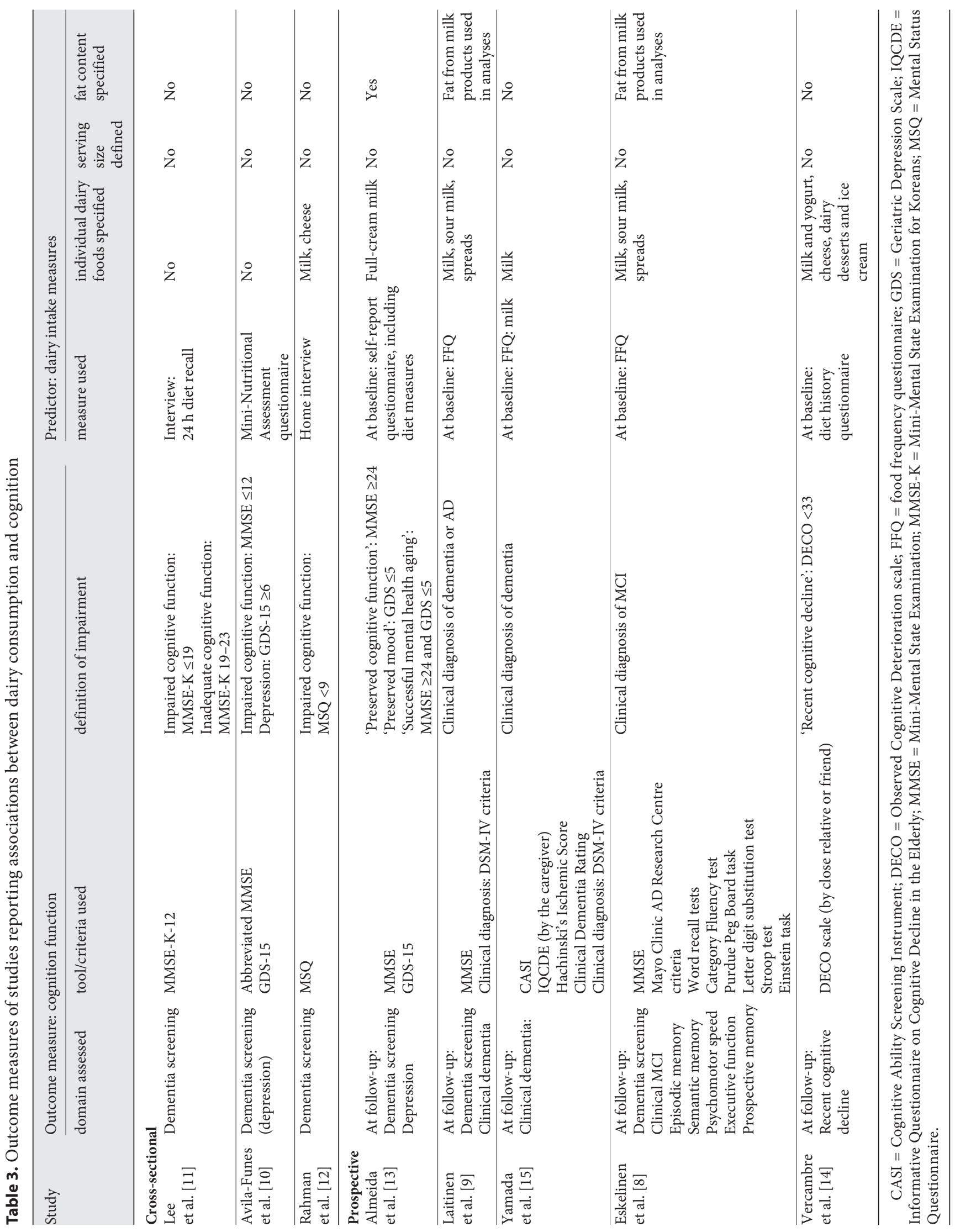


Table 4. Main findings of studies reporting associations between dairy consumption and cognition

\begin{tabular}{|c|c|c|c|c|c|}
\hline Study & $\begin{array}{l}\text { Statistical } \\
\text { analyses }\end{array}$ & $\begin{array}{l}\text { Percentage with } \\
\text { impairment }\end{array}$ & Range of dairy intake & $\begin{array}{l}\text { Main findings with regard to dairy and } \\
\text { cognitive function }\end{array}$ & Secondary findings \\
\hline \multicolumn{6}{|c|}{ Cross-sectional } \\
\hline $\begin{array}{l}\text { Lee } \\
\text { et al. [11] }\end{array}$ & ANOVA & $\begin{array}{l}\text { Cognitive function: } \\
\text { Poor: } 22.3 \% \\
\text { Inadequate } 28.3 \%\end{array}$ & $\begin{array}{l}\text { Milk and dairy products: } \\
\text { absolute amount }\end{array}$ & $\begin{array}{l}\text { Women with poor cognitive function had } \\
\text { significantly lower intakes of milk and dairy } \\
\text { products, } p<0.05 \text {, than those with } \\
\text { inadequate or normal cognitive function } \\
\text { No significant differences for men }\end{array}$ & \\
\hline $\begin{array}{l}\text { Avila-Funes } \\
\text { et al. [10] }\end{array}$ & $\begin{array}{l}\text { Linear } \\
\text { regression }\end{array}$ & $\begin{array}{l}\text { Cognitive impairment: } \\
8.2 \% \\
\text { (Depressive symptoms: } \\
66 \% \text { ) }\end{array}$ & Not specified & $\begin{array}{l}\text { No reported association between cognitive } \\
\text { impairment and milk product consumption }\end{array}$ & $\begin{array}{l}\text { Consumption of milk } \\
\text { products significantly lower } \\
\text { in those with depressive } \\
\text { symptoms }(\mathrm{p}<0.01)\end{array}$ \\
\hline $\begin{array}{l}\text { Rahman } \\
\text { et al. [12] }\end{array}$ & $\begin{array}{l}\text { Logistic } \\
\text { regression }\end{array}$ & $\begin{array}{l}\text { Cognitive impairment: } \\
16.6 \%\end{array}$ & $\begin{array}{l}\text { Cheese and milk: } \\
<1 \text { serving/week or never } \\
\text { to }>1 \text { serving/week }\end{array}$ & $\begin{array}{l}\text { Higher cheese intake associated with } \\
\text { reduced likelihood of cognitive impairment } \\
(\mathrm{OR}=0.68,95 \% \mathrm{CI}=0.47-0.99) \\
\text { Milk intake not associated with cognitive } \\
\text { impairment }\end{array}$ & $\begin{array}{l}\text { Dose-response effect; as } \\
\text { cheese intake increased, } \\
\text { risk of cognitive } \\
\text { impairment decreased }(\mathrm{p}< \\
0.01 \text { ) }\end{array}$ \\
\hline
\end{tabular}

\section{Prospective}

Almeida Cox pro- Impaired cognitive

et al. [13] portional function: $17.6 \%$

hazards (Impaired mood: $8.8 \%$

regression Poor mental health: $24 \%$ )

\begin{tabular}{|c|c|c|c|}
\hline Laitinen & $\begin{array}{l}\text { Logistic } \\
\text { regression }\end{array}$ & Clinical dementia: $4.2 \%$ & Fat intake from milk \\
\hline
\end{tabular}

Full-cream milk: 'regular Consumption of full-cream milk associated consumption' (quantity with impaired cognitive function $(\mathrm{OR}=$ $0.59,95 \% \mathrm{CI}=0.37-0.94$ )
Consumption of full-cream milk associated with poor mental health $(\mathrm{OR}=0.57$, $95 \% \mathrm{CI}=0.37-0.86$ )

\begin{tabular}{llll} 
& & \\
& & \\
& & \\
\hline $\begin{array}{l}\text { Yamada } \\
\text { et al. [15] }\end{array}$ & $\begin{array}{l}\text { Logistic } \\
\text { regression }\end{array}$ & Clinical dementia: 6.4\% & Milk: $<4$ servings/ \\
& & & week to almost daily \\
& & & \\
\hline $\begin{array}{l}\text { Eskelinen } \\
\text { et al. [8] }\end{array}$ & $\begin{array}{l}\text { Logistic } \\
\text { regression }\end{array}$ & Clinical MCI: 5.7\% & $\begin{array}{l}\text { Fat intake from milk } \\
\text { products and spreads, } g\end{array}$ \\
& ANCOVA & &
\end{tabular}

Fat intake from milk products (milk and

sour milk) not significantly associated with

risk of dementia or $\mathrm{AD}$

Moderate intakes of PUFA from spreads

associated with decreased risk of dementia

$(\mathrm{OR}=0.40,95 \% \mathrm{CI}=0.17-0.94)$

Moderate intakes of SFA from spreads

associated with increased risk of dementia

$(\mathrm{OR}=2.45,95 \% \mathrm{CI}=1.10-5.47)$ and $\mathrm{AD}$

$(\mathrm{OR}=3.82,95 \% \mathrm{CI}=1.48-9.87)$

Almost daily milk intake associated with

significantly lower likelihood of vascular

dementia, compared to consuming milk less

than four times per week $(\mathrm{OR}=0.35$,

95\% CI = 0.14-0.77)

High SFA intakes from milk products and

spreads (>21.6 g) associated with increased

risk for MCI compared to those with

intakes less than this $(\mathrm{OR}=2.36,95 \% \mathrm{CI}=$

primarily significant in

women

1.17-4.74)

High SFA from milk products associated

with poorer global cognitive function

(MMSE) $(\mathrm{p}<0.05)$

High total fat from milk products and

spreads associated with poorer

psychomotor speed $(\mathrm{p}<0.05)$

\begin{tabular}{|c|c|c|c|c|c|}
\hline $\begin{array}{l}\text { Vercambre } \\
\text { et al. [14] }\end{array}$ & $\begin{array}{l}\text { Logistic } \\
\text { regression }\end{array}$ & Cognitive decline: $12.4 \%$ & $\begin{array}{l}\text { Mean intakes in g/day; } \\
\text { no consumption } \\
\text { compared with } \\
\text { consumption } \leq \text { median, } \\
\text { and }>\text { median intake }\end{array}$ & $\begin{array}{l}\text { Consumption of dairy desserts and ice } \\
\text { cream associated with cognitive decline } \\
(\mathrm{OR}=1.33,95 \% \mathrm{CI}=1.07-1.65)\end{array}$ & $\begin{array}{l}\text { No significant associations } \\
\text { between milk and yogurt, } \\
\text { and cheese consumption } \\
\text { with cognitive decline }\end{array}$ \\
\hline
\end{tabular}

ANOVA = Analysis of variance; $\mathrm{ANCOVA}=$ analysis of covariance; $\mathrm{BMI}=$ body mass index $\mathrm{CHD}=$ coronary heart disease; $\mathrm{CI}=$ confidence interval; FUD = follow-up duration; MMSE = Mini-Mental State Examination; OR = odds ratio; PUFA = polyunsaturated fatty acids; SFA = saturated fatty acids. 
dairy consumption in terms of cognitive function or MCI/dementia risk. Cross-sectionally, low intakes of milk or dairy products were associated with poorer cognitive function in elderly women [11], but no significant differences for men were found. High cheese intake was associated with lower odds of cognitive impairment in the elderly [12], but no association between milk intake and cognitive impairment was found in 2 studies $[10,12]$. One prospective study indicated that milk intake was associated with a significantly lower likelihood of vascular dementia in older age amongst both men and women [15]

Three studies found adverse effects on cognitive or psychological health from dairy fat. The CAIDE studies did not examine dairy intake per se, but evaluated associations of the fat from milk products and spreads with risk of MCI, dementia, $\mathrm{AD}$, and a number of cognitive domains $[8,9]$. High-saturated or total fat intakes were associated with an increased risk for MCI, poorer global cognitive function and poorer psychomotor speed [8], but not with risk of dementia or AD [9]. Similarly, an Australian study of elderly men demonstrated that whole-fat milk consumption was associated with impaired cognitive function [13], while the final study reported that higher consumption of dairy desserts and ice cream was associated with an increased risk for cognitive decline amongst elderly French women [14]. No significant associations were found between milk and yogurt, or cheese consumption and cognitive decline [14].

Two studies also examined relationships between dairy intake and depression $[10,13]$. A higher prevalence of depressive symptoms was found in men and women with lower milk intakes [10], and whole-fat milk consumption was associated with poor mental health in elderly men [13].

\section{Discussion}

This systematic review identified 8 observational studies that examined the relationship between dairy consumption and cognitive performance. None of the observational studies identified had dairy intake as their primary focus, but instead examined dairy as a component of dietary intake. The limited available literature supports the concept that high dairy consumption may be associated with a lower likelihood of cognitive impairment, however high intakes of full-fat dairy and/or dairy fats may be associated with declines in cognitive performance. The best evidence for elucidating the effects of dairy intake on cognition will come from randomised, clinical intervention studies but there is no evidence available from such studies at present.

\section{Methodological Considerations/Limitations}

There are many limitations to the current research and unanswered questions remain. Given that all of the studies were cross-sectional or prospective in design it is not possible to determine cause and effect of dairy consumption on cognitive measures. The evidence to suggest that a higher consumption of dairy foods may be associated with better cognition is based on a small number of crosssectional research papers, and 1 prospective study. Therefore, definitive conclusions regarding cause and effect between dairy intake and cognition cannot be made.

Most studies (7 out of 8) attempted to control for potential confounding variables, yet 3 of these only adjusted for socio-demographic status. Incomplete adjustment for possible confounding factors might falsely indicate an association. It cannot be ruled out that people who have high dairy intakes might also have other lifestyle characteristics, for example regular exercise habits, which have not been controlled for, and which might account for the relationship with cognitive health. As with any health research, it is often the more 'healthy', or those that are more health conscious, that are interested in volunteering to participate. Similarly, the presence of illness such as vascular disease may influence any relationship between diet and cognition, and needs to be taken into account in any nutritional epidemiology research. Those with poor cognitive function or dementia may have poorer dietary patterns or awareness, which could result in lower dairy intakes. Therefore, the possibility of reverse causation also cannot be ruled out. It remains unknown as to how deteriorating cognition may impact upon food selection or dietary behaviour. The quality of food intake by participants of varying cognitive abilities was not addressed in any of the included studies. The 3 studies that had the most adequate adjustment for confounders had 3 of the highest methodological appraisal scores, were all longitudinal studies and interestingly, were the studies that found associations between dairy fat consumption and cognitive decline $[8,9,14]$.

Despite the wide-ranging use of cognitive measures in the reviewed papers, they were well described, and all provided clear definitions of what constituted 'cognitive impairment or decline', described by either a cut-off score or clinical diagnosis. However, the widespread use in all studies of non-specific global screening tools to measure cognition limits the scope of information available. Many of these screening tools have demographic biases in score 
distributions, have not been suitably validated in community samples representative of the populations evaluated, and do not assess different cognitive domains [16]. These tools also do not typically provide a wide range of scores to assess variability in cognitively healthy populations and are not sensitive to subtle cognitive effects that may occur. Only 1 study reviewed [8] used a battery of standardised psychological tests to assess cognitive function. Thus, while overall relationships between dairy intake and cognitive health were determined, the ability to discriminate between effects on different cognitive domains to determine their clinical relevance is very limited because of the assessment instruments used.

The description of dairy intake, including specific dairy products, average intakes, serving sizes, and fat content were poorly reported in the included studies. Three of the 6 studies which used food frequency questionnaires as the primary dietary measure did not provide a reference for the questionnaire used or report on either reliability or validity $[9,13,15]$. Only 2 papers made reference to the validity of the dietary measure used $[8,14]$. Two studies assessed milk only [13, 15], 1 study assessed milk and cheese [12], and 1 study assessed 5 individual dairy foods (milk, cheese, yogurt, dairy desserts and ice cream) [14]. The 2 CAIDE studies $[8,9]$ also examined intake of milk products, but had more specific aims of examining relationships between dietary fat intake (from milk products and spreads) and cognitive impairment. The papers provided measures of fat intakes (in grams) but total milk intakes were not specified. The studies by Lee et al. [11] and Avila-Funes et al. [10] did not specify the particular foods included within 'dairy products' and 'milk products', respectively. Frequency measures of milk intake in the different studies varied from 'less than once a week' [12] to 'regularly' [13] or 'daily' [15]. However, the actual quantity of milk (or dairy/milk product) consumed on these occasions, as a measure in grams or millilitres, was not specified.

No studies specified the amount, in grams or in a defined serving size (of total dairy or individual dairy products), that was associated with either a detrimental or beneficial cognitive outcome. This lack of information makes it difficult to draw conclusions regarding the optimal intake of dairy that may be associated with greater cognitive health, to directly compare outcomes of studies, or to determine whether the fat content of dairy is important in mediating any relationship between diet and cognition. Only 1 study specified the fat content of dairy [13]. Despite the CAIDE studies assessing the fat content of milk products in relation to cognition, the actual fat content was not stipulated $[8,9]$. The remaining
2 prospective studies $[14,15]$ both measured dietary intake at baseline and had extensive follow-up times (13-30 years), and so it is most likely that the dairy consumed was whole fat, as the dietary measures were undertaken before the widespread increase in the availability of reduced fat dairy products. The measurement of diet at baseline only, as done in all included prospective studies, may not accurately reflect long-term consumption patterns, as dietary habits may not remain stable.

Possible Mechanisms of Dairy-Cognition Relationship

The vascular hypothesis of dementia, implicating neurovascular dysfunction as a fundamental part of dementia, has recently emerged from epidemiological, clinical and pathological studies [17]. Vascular pathological changes associated with ageing and cognitive impairment are also common to a number of vascular diseases. Vascular alterations such as white matter lesions have been associated with lower performance in frontal lobe tasks, including attention, memory, executive function, cognitive flexibility, sensorimotor ability, and processing speed [1824]. This is supported by a recent systematic review which concluded that type 2 diabetes, hypertension, dyslipidemia and obesity are associated with declines in cognitive performance, namely processing speed, mental flexibility, and memory, in non-demented populations [25].

Dairy may reduce the risk for cognitive impairment by modifying vascular factors linked to these detrimental brain changes, particularly via weight reduction. Epidemiological studies, animal studies and a small number of randomised trials provide evidence for an anti-obesity effect of calcium and dairy foods [26-29]. In addition to calcium, bioactive compounds derived from whey protein in dairy may contribute to accelerating weight and fat loss [26, 28-30].

Other components of dairy may play a role in reducing metabolic risk. Dairy products are the primary dietary source of vitamin D [31], which through its role in regulating calcium homeostasis may improve insulin sensitivity and glucose homeostasis [31, 32]. Phosphorus and magnesium are involved in blood pressure regulation [33, 34]. Magnesium may also modulate vascular function through its antioxidant and anti-inflammatory properties [35]. There is also evidence to suggest that increasing dietary intake of magnesium may also help reduce cholesterol and triglycerides [36], and improve diabetes control, due to its role in glucose homeostasis [37, 38]. These components of dairy may help to prevent or decrease the vascular alterations and structural brain changes that occur with cognitive decline. 
The beneficial effects of these components of dairy on vascular disease may also be mediated by an improvement in inflammatory state. Individuals with greater adiposity have an increased inflammatory state in comparison with their leaner counterparts $[39,40]$ which has been linked with adverse cognitive function [41-43]. Any decrease in inflammation (via weight loss, improved regulation of glucose and blood pressure) may subsequently reduce the risk for cognitive decline.

\section{Conclusions}

Despite considerable methodological variability and incomplete adjustment for covariates in some studies, findings from 2 cross-sectional and 1 prospective study suggest that dairy consumption may have a beneficial effect on cognitive function. The role of dairy-derived nutrients in the regulation of vascular pathological changes associated with ageing and cognitive impairment may underlie these associations. Conversely, findings from 4 prospective studies suggest that the consumption of whole-fat dairy products may be associated with cognitive decline in the elderly, implicating saturated fat, in particular, in this relation- ship. A number of study limitations including the measures of both cognition and dairy intake reduce the ability to draw conclusions from this collection of research.

There have been no studies to date examining the relationship between dairy intake and cognitive function in a healthy adult population across all ages. The quality of evidence from future observational studies would be improved if detailed assessments of both diet and cognition at multiple time periods (well before the onset of cognitive decline) were included. Regular assessment and recording of dairy intake is needed, distinguishing highfrom low-fat dairy, and reporting dairy intake in grams per day. Future studies should include a very thorough assessment of cognition, including tests on a range of cognitive domains. It is imperative that any future research control for all potential confounding variables, including not only socio-demographics, but lifestyle factors and vascular health. Prospective studies of sufficient duration, with detailed assessment of both diet and cognition over time, would greatly enhance understanding of the possible association between dairy and cognitive functioning. More conclusive evidence is needed from wellcontrolled, long-term intervention trials to confirm whether dairy intake can improve cognitive functioning.

Appendix. Methodological appraisal scores for the included studies

\begin{tabular}{|c|c|c|c|c|c|c|c|c|c|c|c|c|c|c|c|c|c|c|c|c|c|}
\hline Author & 1 & 2 & 3 & 4 & 5 & 6 & 7 & 8 & 9 & 10 & 11 & 12 & 13 & 14 & 15 & 16 & 17 & 18 & 19 & 20 & $\mathrm{~T}$ \\
\hline \multicolumn{22}{|l|}{ Cross-sectional } \\
\hline Lee et al. [11] & 0 & 1 & $1 / 2$ & 1 & 0 & $1 / 2$ & 1 & 0 & $1 / 2$ & 0 & 0 & 1 & 0 & 1 & 1 & 0 & 1 & 0 & 0 & 0 & 8.0 \\
\hline Avila-Funes et al. [10] & 1 & 1 & 0 & 1 & $1 / 2$ & 0 & 1 & 0 & 0 & 0 & 0 & 1 & 0 & 1 & 1 & 0 & 1 & 0 & 0 & 1 & 9.5 \\
\hline Rahman et al. [12] & 1 & 1 & 0 & 1 & $1 / 2$ & 0 & $1 / 2$ & 0 & 0 & $1 / 2$ & 0 & 1 & 0 & 1 & 1 & 1 & 1 & 1 & 0 & 1 & 11.5 \\
\hline \multicolumn{22}{|l|}{ Prospective } \\
\hline Almeida et al. [13] & 1 & 1 & 0 & 0 & 1 & 0 & $1 / 2$ & 0 & 0 & 1 & 0 & 1 & 0 & 1 & 1 & 0 & 1 & 1 & 0 & 1 & 10.5 \\
\hline Laitinen et al. [9] & 1 & 1 & $1 / 2$ & 0 & $1 / 2$ & 0 & $1 / 2$ & 0 & 0 & 1 & 0 & 1 & 0 & 1 & 1 & 1 & 1 & 1 & 0 & 1 & 11.5 \\
\hline Yamada et al. [15] & 0 & $1 / 2$ & 0 & 1 & 1 & 1 & $1 / 2$ & 0 & 0 & $1 / 2$ & 0 & 1 & 1 & 1 & 1 & 1 & 1 & 1 & 0 & 0 & 11.5 \\
\hline Eskelinen et al. [8] & $1 / 2$ & $1 / 2$ & $1 / 2$ & 0 & $1 / 2$ & 0 & 1 & $1 / 2$ & 0 & 1 & 0 & 1 & 1 & 1 & 1 & 1 & 1 & 1 & 0 & 1 & 12.5 \\
\hline Vercambre et al. [14] & 1 & 1 & 1 & 1 & 1 & 1 & $1 / 2$ & 1 & 1 & $1 / 2$ & 0 & 1 & 0 & 1 & 1 & 1 & 1 & 1 & 0 & 1 & 16.0 \\
\hline
\end{tabular}

$1=$ Yes; 0 = no; $1 / 2$ = partly; $\mathrm{T}=$ total.

\section{References}

1 United Nations: World Population Ageing 1950-2050. New York, United Nations, 2001.

$\checkmark 2$ Petersen RC, Smith GE, Waring SC, Ivnik RJ, Tangalos EG, Kokmen E: Mild cognitive impairment: clinical characterization and outcome. Arch Neurol 1999;56:303-308.
Ferri CP, Prince M, Brayne C, Brodaty $\mathrm{H}$, Fratiglioni L, Ganguli M, Hall K, Hasegawa K, Hendrie H, Huang Y, Jorm A, Mathers C, Menezes PR, Rimmer E, Scazufca M: Global prevalence of dementia: a Delphi consensus study. Lancet 2005;366:2112-2117.
Bryan J: Mechanisms and evidence for the role of nutrition in cognitive ageing. Ageing Int 2004;29:28-45.

5 Solfrizzi V, Panza F, Capurso A: The role of diet in cognitive decline. J Neural Transm 2003;110:95-110. 
-6 Tooth L, Ware R, Bain C, Purdie DM, Dobson A: Quality of reporting of observational longitudinal research. Am J Epidemiol 2005; 161:280-288.

$\checkmark 7$ Hayden JA, Cote P, Bombardier C: Evaluation of the quality of prognosis studies in systematic reviews. Ann Intern Med 2006; 144: 427-437.

-8 Eskelinen MH, Ngandu T, Helkala EL, Tuomilehto J, Nissinen A, Soininen H, Kivipelto M: Fat intake at midlife and cognitive impairment later in life: a population-based CAIDE study. Int J Geriatr Psychiatry 2008; 23:741-747.

-9 Laitinen MH, Ngandu T, Rovio S, Helkala EL, Uusitalo U, Viitanen M, Nissinen A, Tuomilehto J, Soininen H, Kivipelto M: Fat intake at midlife and risk of dementia and Alzheimer's disease: a population-based study. Dement Geriatr Cogn Disord 2006;22: 99-107.

10 Avila-Funes JA, Garant MP, Aguilar-Navarro S: Relationship between determining factors for depressive symptoms and for dietary habits in older adults in Mexico. Rev Panam Salud Publica 2006;19:321-330.

-11 Lee L, Kang SA, Lee HO, Lee BH, Park JS, Kim JH, Jung IK, Park YJ, Lee JE: Relationships between dietary intake and cognitive function level in Korean elderly people. Pub lic Health 2001;115:133-138.

12 Rahman A, Sawyer Baker P, Allman RM, Zamrini E: Dietary factors and cognitive impairment in community-dwelling elderly. J Nutr Health Aging 2007;11:49-54.

$\checkmark 13$ Almeida OP, Norman P, Hankey G, Jamrozik K, Flicker L: Successful mental health aging: results from a longitudinal study of older Australian men. Am J Geriatr Psychiatry 2006;14:27-35.

14 Vercambre MN, Boutron-Ruault MC, Ritchie K, Clavel-Chapelon F, Berr C: Longterm association of food and nutrient intakes with cognitive and functional decline: a 13year follow-up study of elderly French women. Br J Nutr 2009; 102:419-427.

15 Yamada M, Kasagi F, Sasaki H, Masunari N, Mimori Y, Suzuki G: Association between dementia and midlife risk factors: the radiation effects research foundation adult health study. J Am Geriatr Soc 2003;51:410-414.

16 Cullen B, O'Neill B, Evans JJ, Coen RF, Lawlor BA: A review of screening tests for cognitive impairment. J Neurol Neurosurg Psychiatry 2007;78:790-799.

17 Dickstein DL, Walsh J, Brautigam H, Stockton SD Jr, Gandy S, Hof PR: Role of vascular risk factors and vascular dysfunction in Alzheimer's disease. Mt Sinai J Med 2010;77: 82-102.

- 18 Akisaki T, Sakurai T, Takata T, Umegaki H, Araki A, Mizuno S, Tanaka S, Ohashi Y, Iguchi $\mathrm{A}$, Yokono $\mathrm{K}$, Ito $\mathrm{H}$ : Cognitive dysfunction associates with white matter hyperintensities and subcortical atrophy on magnetic resonance imaging of the elderly diabetes mellitus Japanese elderly diabetes intervention trial (J-EDIT). Diabetes Metab Res Rev 2006;22:376-384.
19 Soderlund H, Nilsson LG, Berger K, Breteler MM, Dufouil C, Fuhrer R, Giampaoli S, Hofman A, Pajak A, de Ridder M, Sans S, Schmidt R, Launer LJ: Cerebral changes on MRI and cognitive function: the cascade study. Neurobiol Aging 2006;27:16-23.

20 Verdelho A, Madureira S, Ferro JM, Basile AM, Chabriat H, Erkinjuntti T, Fazekas F, Hennerici M, O’Brien J, Pantoni L, Salvadori E, Scheltens P, Visser MC, Wahlund LO, Waldemar G, Wallin A, Inzitari D, Study L: Differential impact of cerebral white matter changes, diabetes, hypertension and stroke on cognitive performance among non-disabled elderly. The LADIS study. J Neurol Neurosurg Psychiatry 2007;78:1325-1330.

21 Wright CB, Festa JR, Paik MC, Schmiedigen A, Brown TR, Yoshita M, DeCarli C, Sacco R, Stern Y: White matter hyperintensities and subclinical infarction: associations with psychomotor speed and cognitive flexibility. Stroke 2008;39:800-805.

22 Rabbitt P, Mogapi O, Scott M, Thacker N, Lowe C, Horan M, Pendleton N, Jackson A, Lunn D: Effects of global atrophy, white matter lesions, and cerebral blood flow on age-related changes in speed, memory, intelligence, vocabulary, and frontal function. Neuropsychology 2007;21:684-695.

-23 Tiehuis AM, Vincken KL, van den Berg E, Hendrikse J, Manschot SM, Mali WP, Kappelle LJ, Biessels GJ: Cerebral perfusion in relation to cognitive function and type 2 diabetes. Diabetologia 2008;51:1321-1326.

24 Breteler MM, van Amerongen NM, van Swieten JC, Claus JJ, Grobbee DE, van Gijn J, Hofman A, van Harskamp F: Cognitive correlates of ventricular enlargement and cerebral white matter lesions on magnetic resonance imaging. The Rotterdam study. Stroke 1994;25:1109-1115.

25 van den Berg E, Kloppenborg RP, Kessels RP, Kappelle LJ, Biessels GJ: Type 2 diabetes mellitus, hypertension, dyslipidemia and obesity: a systematic comparison of their impact on cognition. Biochim Biophys Acta 2009; 1792:470-481.

26 Zemel MB: Role of calcium and dairy products in energy partitioning and weight management. Am J Clin Nutr 2004;79:907S912S.

27 Zemel MB, Teegarden D, Van Loan MD, Schoeller DA, Matkovic V, Lyle RM, Craig BA: Dairy-rich diets augment fat loss on an energy-restricted diet: a multicenter trial. Nutrients 2009;1:83-100.

28 Teegarden D: The influence of dairy product consumption on body composition. J Nutr 2005;135:2749-2752.

29 Zemel MB: The role of dairy foods in weight management. J Am Coll Nutr 2005;24:537S$546 \mathrm{~S}$.

30 Luhovyy BL, Akhavan T, Anderson H: Whey proteins in the regulation of food intake and satiety. J Am Coll Nutr 2007;26:704S-712S.
31 Teegarden D, Donkin SS: Vitamin D: emerging new roles in insulin sensitivity. Nutr Res Rev 2009;22:82-92.

32 von Hurst PR, Stonehouse W, Coad J: Vitamin D supplementation reduces insulin resistance in South Asian women living in New Zealand who are insulin resistant and vitamin $\mathrm{D}$ deficient - a randomised, placebocontrolled trial. Br J Nutr 2010;103:549-555.

- 33 Alonso A, Nettleton JA, Ix JH, de Boer IH, Folsom AR, Bidulescu A, Kestenbaum BR, Chambless LE, Jacobs DR Jr: Dietary phosphorus, blood pressure, and incidence of hypertension in the atherosclerosis risk in communities study and the multi-ethnic study of atherosclerosis. Hypertension 2010;55:776784 .

34 Sontia B, Touyz RM: Role of magnesium in hypertension. Arch Biochem Biophys 2007; 458:33-39.

35 Weglicki WB, Mak IT, Kramer JH, Dickens BF, Cassidy MM, Stafford RE, Philips TM: Role of free radicals and substance $p$ in magnesium deficiency. Cardiovasc Res 1996;31: 677-682.

- 36 Singh RB, Rastogi SS, Sharma VK, Saharia RB, Kulshretha SK: Can dietary magnesium modulate lipoprotein metabolism? Magnes Trace Elem 1990;9:255-264

37 Ma B, Lawson AB, Liese AD, Bell RA, MayerDavis EJ: Dairy, magnesium, and calcium intake in relation to insulin sensitivity: approaches to modeling a dose-dependent association. Am J Epidemiol 2006;164:449458.

38 Saris NE, Mervaala E, Karppanen H, Khawaja JA, Lewenstam A: Magnesium. An update on physiological, clinical and analytical aspects. Clin Chim Acta 2000;294:1-26.

- 39 Festa A, D’Agostino R, Williams K, Karter AJ, Mayer-Davis EJ, Tracy RP, Haffner SM: The relation of body fat mass and distribution to markers of chronic inflammation. Int J Obes 2001;25:1407-1415.

40 Pannacciulli N, Cantatore FP, Minenna A, Bellacicco M, Giorgino R, De Pergola G: Creactive protein is independently associated with total body fat, central fat, and insulin resistance in adult women. Int J Obes 2001; 25:1416-1420.

- 41 Schmidt R, Schmidt H, Curb JD, Masaki K, White LR, Launer LJ: Early inflammation and dementia: a 25 -year follow-up of the Honolulu-Asia Aging Study. Ann Neurol 2002; 52:168-174

42 Yaffe K, Kanaya A, Lindquist K, Simonsick EM, Harris T, Shorr RI, Tylavsky FA, Newman AB: The metabolic syndrome, inflammation, and risk of cognitive decline. JAMA 2004;292:2237-2242.

-43 Yaffe K, Lindquist K, Penninx BW, Simonsick EM, Pahor M, Kritchevsky S, Launer L, Kuller L, Rubin S, Harris T: Inflammatory markers and cognition in well-functioning African-American and white elders. Neurology 2003;61:76-80. 